\title{
The VUCAlity of Projects: A New Approach to Assess a Project Risk in a Complex World
}

\author{
Thordur Vikingur Fridgeirsson *, Helgi Thor Ingason (1), Haukur Ingi Jonasson and Bara Hlin Kristjansdottir
}

School of Technology, Reykjavík University, 102 Reykjavik, Iceland; helgithor@ru.is (H.T.I.); haukuringi@ru.is (H.I.J.); bara.kristjansdottir@marel.com (B.H.K.)

* Correspondence: thordurv@ru.is

check for updates

Citation: Fridgeirsson, T.V.; Ingason, H.T.; Jonasson, H.I.; Kristjansdottir, B.H. The VUCAlity of Projects: A New Approach to Assess a Project Risk in a Complex World. Sustainability 2021, 13, 3808. https:// doi.org/10.3390/su13073808

Academic Editor: Marc A. Rosen

Received: 21 January 2021

Accepted: 7 March 2021

Published: 30 March 2021

Publisher's Note: MDPI stays neutral with regard to jurisdictional claims in published maps and institutional affiliations.

Copyright: (c) 2021 by the authors. Licensee MDPI, Basel, Switzerland. This article is an open access article distributed under the terms and conditions of the Creative Commons Attribution (CC BY) license (https:// creativecommons.org/licenses/by/ $4.0 /)$.

\begin{abstract}
The "projectification" of Western societies has been consolidated by a number of studies and now calls for various adaptations in the managerial framework of project management. Faster rates of change in complex environments antagonize the traditional risk assessment approach and demand a more dynamic approach. A framework commonly used for understanding the challenges of complexity in the modern business environment is VUCA. VUCA stands for volatility, uncertainty, complexity, and ambiguity. In order to mitigate the impact of a VUCA environment on complex projects, organizations and project leaders need to know the type and severity of challenges they are dealing with in each unique project. This study explores the VUCA framework in the context of projects and suggests that the VUCA approach can enhance the conventional risk assessment procedure. The study also drafts an accessible diagnostic tool to assess the VUCA dimensions a project is facing, so that project managers can effectively isolate "fat tail" risk events. The tool is tested on five complex projects in the manufacturing industry and its effectiveness is discussed.
\end{abstract}

Keywords: project preparation; decisions; risk assessment; risk management; VUCA

\section{Introduction}

Organizations increasingly use projects as a vehicle for transformation and implementation of strategic initiatives with the aim to stay competitive. This trend is generally recognized as "projectification" of an organization, a term that was arguably first mentioned in this context in 1995 by Christophe Midler [1]. The term refers to the transition from classical functional organizations in the 1960s to more project coordination-orientated organizations in the 1970s and the deep impact these changes have had on task definitions, hierarchic regulations, carrier management, functions, and relations with suppliers. Therefore, "projectification" is the way to adapt these permanent processes to the new context. It is also used in the public and global domains to describe the shift towards more emphases on projects and project management. Wald et al. [2] and Schoper et al. [3] developed a formula to measure the share of project work (in working hours) as a ratio of total work within national economies and concluded that more than a third of all work within the countries under investigation was project related. Morris et al. [4] argued for seven important characteristics of contemporary project management as a discipline: (1) the interest in the history and distinct theory for projects; (2) the awareness of the importance of context or how a project is a part of the social and sectoral enterprise (firm); (3) interest in understanding how projects and organizations are linked; (4) interest in how strategy and projects are linked; (5) interest in how projects are used as vehicles to innovate for the future; (6) interest in the role of leadership and the role of human behavior in shaping trust and a cooperative atmosphere; and (7) interest in seeing projects as complex, risky, cross-firm relationships, that are used to adopt to uncertain and novel ventures that have special challenges with regards to learning and knowledge integration. The seventh characteristic is of special interest for this study. 
Risk assessment and the management of risk are naturally of major interest in the field of project management. In general, there is increased awareness of the need to manage risk in organizations. This trend shows, for instance, in the way the most widespread management standards, such as ISO 9001, ISO 1001, and ISO 45001, have evolved in their latest revisions, and through the emergence and, presumably, increased application of the ISO 31000 standard on risk management [5].

Moreover, projects are notorious for cost overruns and problems during the implementationsee, for instance, the work of Bent Flyvbjerg and associates on risk and accurate forecasting [6,7]. It is known that flawed decisions in the project preparation phase can result in costly and significant problems in the project implementation. Risk detection, risk management, and risk control are, therefore, important parts of sound project governance at the design phase of the project. Other challenges facing people who are attempting to assess risks can, among other things, be tunnel vision and cognitive biases such as over-optimism that can block rationality and realistic perceptions $[5,6]$. This leads to query if the traditional methods of risk detection and management in projects can be modified to include a more truthful detection of highly impacting events.

Traditional risk assessment models generally include evaluating the likelihood of occurrence of risk events and the impact of such an event if it occurs as numerical values. By multiplication, the coefficient of the risk is decided, the highest value presenting the most significant risk event to manage and mitigate. This approach is, for example, the methodology proposed in the PMI's PMBOK [8] and the PMI's Standard for Risk Management in Portfolios, Programs, and Projects [9]. The same attitude can be perceived in the APM body of knowledge that states the following: "risk analysis and risk management is a process that allows individual risk events and overall risk to be understood and managed proactively, optimizing success by minimizing threats and maximizing opportunities and outcomes" [10].

The conventional probabilistic and event-based approaches to risk assessment are great and have proved its usefulness. It does, however, have its limitations, especially when it comes to unpreceded events involving low-probability/high-impact risks, system risks, and risks that are less technical and more psychological/social in nature. Noteworthy is the study by Ackermann et al., who presented the "risk filter" that uses insights from forensics to identify risk exposure on future projects and tackle them [11]. Another important perspective comes from Nassim Nicholas Taleb, who argued that the risks that really do shape our world are rare events that have a high "tail risk" and can hence be deemed as "black swan" events. He wanted to explain the impact of high-profile, unpredicted, and rare events that are totally surprising, the difficulty of scientifically computing, due to very low occurrence, the probability of extremely rare events, and the biases that blind decision makers to uncertainty and to a rare event's impacts. The global COVID-19 pandemic is an example of a "tail risk" and "black swan" event [12]. As conventional risk approaches in risk identification in project management are unlikely to detect "black swan" problems, a new paradigm might come in handy.

This paper presents an alternative and complementary method to assess risk in projects by categorizing the project risks in predefined risk groups that indicate the VUCA (volatility, uncertainty, complexity, ambiguity) nature of the risk for the project under screening. VUCA has, in recent years, become a popular concept in contemporary management science [13]. When applied to project management, the VUCA approach separates different types of challenges that projects might face. Instead of searching for sporadic risk events that might jeopardize the project scope, the risk manager who uses a VUCA approach would constantly look for the VUCAlity of the project, i.e., volatility of uncertainty, complexity, and ambiguity, that might impact the project or program. In short, the project risk is measured as the VUCA impact of the endeavor under screening. With a clear view of which element of VUCA affects a project, and to what degree, decision makers and project managers would be much better equipped to effectively allocate limited resources 
to achieve successful outcomes. In challenging environments, the VUCAilty method helps to better isolate the high-impact events for hedging and control.

This study asks whether a VUCA risk assessment could be achieved by applying a relatively simple questionnaire applied in the pre-project decision stage as to determine metrics for the project's VUCAlity. Furthermore, it attempts to determine the functionality and real-world application of this tool by testing it on five large and technical challenging projects.

The importance of a careful risk assessment is greatest at the beginning of a project, in the design phase, before execution begins. Decision makers and project managers, therefore, would benefit greatly from knowing as much as possible during initial analysis on the undercurrents shaping the project. A VUCA risk assessment could support proactive project management and serve as a valuable addition to enhance project risk awareness.

\section{Project Risks, Complexity, and VUCAlity}

Project risk can entail structural complexity due to many elements (stakeholders, workstreams, etc.) or dynamic complexities due to any detrimental property of a complex system where internal or external behavioral influences between constituents can alternate over the course of time [14-16]. Further, project risks can be linked to uncertainties that are inescapable (aleatoric risk) and to uncertainties since the decision makers are not able to know the things that make a situation uncertain (epistemic risk). From a narrow project management perspective, project risk can evolve around a variety of uncertainties regarding the project scope [14,16-20], outcome [14,16,17], change [21-23], performance [14,16,19,24], technologies [14,16,18,25], stakeholders [14,18,24], interdependences [14,19,21,24], organizational issues [23], etc. From wider perspectives, project risks might evolve around a variety of uncertainties regarding the PESTLIED (political, economic, social, technological, legal, international, environmental, and demographic) aspects of the environment that could impact and impose risk on the project and program. Finally, as stated by Jonasson and Ingason, projects and programs-as well as the project leader, project team, the project organization, the project host society (both locally and with regards to wider aspects), the field of project management profession as such — can be exposed to ethical risks of various kinds, even with implications for future generations, animals, and nature [26].

Project complexity is a topic in project management research that has received considerable attention and there has been an ongoing search for more improved approaches to manage it $[27,28]$. The search has ranged from examining the intersection of complexity theory and project management to mapping specific complexities to specific competences for project managers, and project management research has endeavored to shed light on the best approaches and practices to deal with the ever-changing and increasingly complex environment of projects in the modern business environment [29,30]. One of the challenges encountered by researchers who study complexity is the difficulty in defining what, exactly, complexity is. Various approaches and research studies have attempted to either narrow down the field of application or propose definitions that add dimensions to the understanding of complexity. For example, regarding project management, M. Bosch-Rekveldt et al. proposed a framework for the elements that contribute to project complexity in large engineering projects, effectively limiting the field of vision to a specific type of project within a specific industry [29].

Another model of project complexity, proposed by Remington, Zolin, and Turner [18], distinguishes dimensions of complexity based on severity, in order to address the fact that the "wide range of factors that may contribute to project complexity [ ... ] are in turn subject to a range of severity factors." By separating the dimensions of complexity and severity, they aimed to improve the robustness of the model's measurements [18]. They also discussed the existing literature on complexity in depth and proceeded to "propose an operational distinction between the terms dimensions of complexity, which tells us where the complexity comes from and the severity, which tells us to what extent it will be a problem" [18]. 
The VUCA approach originates from Warren Bennis and Burt Nanus's book "Leaders: Strategies for Taking Charge" where the acronym VUCA stands for volatility, uncertainty, complexity, and ambiguity [30]. According to the U.S. Army Heritage and Education Center, the VUCA acronym has been used within the U.S. Army War College for leadership training. It is often cited in U.S. Army War College documents and became popular in strategic and leadership research throughout the 1990s [31]. The VUCA term has made its way into the business lexicon, with popular explanatory articles appearing in publications such as the Harvard Business Review [32] and Forbes [33].

In 2016, Szpitter and Sadkowska proposed VUCA as a useful matrix for understanding and assessing project environment complexity and risk [34]. Another paper argued that why projects fail is due to the project complexity of the modern VUCA world, and through a survey, the authors found out that stakeholders do not often treat project complexity with due respect but with ignorance (in their word "stupidity") [35]. In 2016, the book "Managing in a VUCA World" took a close look at volatility, uncertainty, complexity, and ambiguity (VUCA) as concepts and frameworks to understand and manage unpredictability and rapid change [36]. It links VUCA to complexity and suggests ways to manage it. It looks at strategy and planning in the VUCA environment, marketing and sales, operations and cost management, global supply chains, control, organizational structure, process management, and IT management. One chapter of the book, written by Mack and Jungen, looks at program and project management in VUCA environments specifically [36]. Others, as to rethink project management in an era of digital transformation linked to the VUCA environment, have focused on project management curricula and the development of the project management profession until 2030 [37].

This study bases its definition of the VUCA components on Bennett and Lemoine, who used VUCA to describe the rapidly changing environment that modern businesses must navigate in [32,38]. They warn against conflating the distinct terms of the VUCA framework when one is faced with the unpredictability of VUCA situations. Despite the myriad popular articles, they claimed, "there is a lack of information regarding just what it is that leaders should do in order to confront ( . . ) these conditions" [38]. Properly identifying them, they claimed, is crucial to take an appropriate action, as they each "require their own separate and unique responses. ( ... ) Failure to use the right label will lead to a misallocation of what could be considerable corporate resources" [38]. Based on this, a definition of each of the VUCA terms is summarized in Table 1 (a more detailed version of the table can be found in Appendix A).

Table 1. A suggestion of a general VUCA framework for projects. Adapted from Bennett and Lemoine [38].

\begin{tabular}{llll}
\hline & What Is It? & Example & How to Address It? \\
\hline Volatility & $\begin{array}{l}\text { Changes are frequent } \\
\text { and unpredictable }\end{array}$ & Prices, stocks, politics, economy & $\begin{array}{l}\text { Adopt change management and } \\
\text { agile methods }\end{array}$ \\
\hline Uncertainty & $\begin{array}{l}\text { The impact of future events } \\
\text { not known }\end{array}$ & $\begin{array}{l}\text { Climate changes impact } \\
\text { on infrastructure }\end{array}$ & $\begin{array}{l}\text { Information analysis bypassing } \\
\text { cognitive biases }\end{array}$ \\
\hline Complexity & Many inter-connections and levels & $\begin{array}{l}\text { Many sub-contractors, } \\
\text { connected tasks }\end{array}$ & $\begin{array}{l}\text { Decomposing the project, } \\
\text { rolling planning }\end{array}$ \\
\hline Ambiguity & $\begin{array}{l}\text { Lack of knowledge, unclear what } \\
\text { to expect }\end{array}$ & Fake news, social media & Integrity, communication, psychology \\
\hline
\end{tabular}

\section{Method}

The topic posed in this paper is to define whether it is possible to build a "VUCA meter" to gauge the severity of each VUCA dimension's impact on a project. The project attempts to measure the severity and impact strength of each VUCA attribute and produce a numerical value as to measure the VUCAlity of a project and the severity of each VUCA dimension. The VUCA concepts, derived from Bennett and Lemoine [32,38], are summarized as the following statements: 
- Volatility: Unstable and unpredictable resource cost and/or availability at unpredictable times and durations, expected fluctuations on resources with unknown timing and magnitude. Questions aim to capture key reasons why resources might be suddenly unavailable or expensive, and the challenges in resolving resourcing for unforeseen new needs.

- Uncertainty: Lack of knowledge and unclear impact of change, but cause and effect are known. Questions aim to capture key risks for lack of comprehensive and reliable knowledge in projects, or difficulty in communicating or accessing relevant information, or effectively resolving questions on unforeseen new issues.

- Complexity: Many interconnected parts, complex regulatory/political environments, multiple components, and parts.

- Questions aim to capture key risks for the structural or systems-related complexity in the environment, internal and external, of a project, as well as whether an appropriate governance to effectively deal with these complexities is in place.

- Ambiguity: Doubt about the nature of cause and effect, little to no historical information available as to predict outcome, hence difficult to forecast or plan for.

- Questions aim to capture whether there are risks due to lack of experience and predictability that might affect the project, and whether the project delivers unpredictable new changes, either internal or external, to the project and/or the organization.

The methodology selected to define this VUCA meter and try it out was a questionnaire in the form of statements and a Likert rating scale for answers [39]. The dimension of "complexity", for instance, refers to the statement in the questionnaire, as an indicator of where the complexity comes from. The premise is that each statement in the proposed questionnaire should be applicable to any complex project or activities to be carried out for any complex project, to a greater or lesser degree, according to the standard of projects as described by the Project Management Institute's PMBOK [8].

The VUCA rating scale measures the severity of each subject's estimation of complexity in the dimension of the project or project activities that is being investigated. A five-point range was selected, and in order to maintain the questionnaire's accuracy, the number of questions per VUCA attribute was the same. It is assumed that the evaluated statements have a high internal consistency and so a high-score answer to one question would have the same weight on a total score as a high-score answer to any other question (interval range). This is a limitation of Likert scales in general, but trends in weights across categories and different subjects will be examined in the results to test that assumption. Building on the definitions by Bennett and Lemoine, key components of each distinct VUCA term were defined and statements were formed on typical questions in previously discussed risk assessment questionnaires. The statements were then grouped and scored based on the relation to the type of risk associated with a given VUCA term. The resulting questionnaire took the form of five statements per VUCA concept, each with a 5-point answer range with numerical weights as interval variables. The answers are: Strongly agree (1), Agree (2), Neither agree nor disagree (3), Disagree (4), and Strongly disagree (5). An interval scale such as this has ordered numbers with meaningful divisions. In order to give a result that can be averaged, the relative weight of the ratings and statements needed to be as equal as possible. The answer scores were then summed and averaged for each group as a total average score for how VUCA the project may be seen.

Closed statement questionnaires with rating scales are a form of qualitative research that delivers quantitative results based on subjective evaluation. Each answer was based on the evaluation of the person answering the survey, which can be influenced by that individual's perceptions, experiences, or emotions. The resulting data took a numerical form, which might provide a measure of consistency and measurability. This makes the results easier to evaluate and provided an added benefit in use, e.g., for an organization that wishes to see trends over time.

The design of the questionnaire was conducted in such a fashion that it would give sound results and accurate answers to the research question. Validity in the research was 
related to the appropriateness and accuracy of the research instrument used to measure the given reality. Ethical considerations in the research were related to an informed and unrestricted consent from participants and the organization. Participants in the survey received a link via email and thus had full freedom to refuse or discontinue participation at any time. They were informed about the purpose of the research and how the results would be used, and they read a statement of confidentiality.

\section{Results}

The study is based on a convenience sample. The five project managers who were strategically chosen to try the suggested VUCA risk measure on projects belonged to one globally operating manufacturing organization. The organization is one of the leading players worldwide in developing, designing, installing, and integrating turn-key solutions for the food industry. All but one of the projects were evaluated as being of the highest risk level according to the company's risk standards. All the five project managers have extensive experience in leading large international projects and programs. The projects managers gave answers to the questionnaire without seeing the evaluated score. The outcomes were compared and discussed with the participants in the survey, in order to evaluate whether the meter presented an accurate or inaccurate outcome. Each evaluation took place in an individual interview. Evaluation of results was a combination of subjective evaluation (categorizing accuracy as high, medium, or low) with notes for improvement, and comparison to project actuals (time, cost, etc.). As evaluations were partly subjective, the average score accuracy should indicate whether the intervals and statement categories were correct. Based on the evaluation, a strength rating of High, Medium, or Low was given to each category's average result. Based on those evaluations, the meter was adjusted. A first version of a VUCA meter was then presented for future testing and conclusions were drawn as to whether it can serve as a rough indicator of how much and where in the VUCA matrix a project is situated in the future. The projects that were examined with the VUCA risk assessment meter were:

- Project 1: A complex high-tech engineering project-technically advanced highcapacity production line-conducted in collaboration with multiple other organizations.

- $\quad$ Project 2: A new enterprise resource planning (ERP) implementation project.

- Project 3: A complex high-tech engineering project-technically advanced highcapacity production line.

- Project 4: A complex high-tech engineering project-technically advanced highcapacity production line.

- Project 5: A complex high-tech engineering project-technically advanced highcapacity production line.

Even though all the projects share some similar characteristics regarding complexity, budget, and timeline, they each entail a unique development unrelated to the others (including different technology, geography). Project budgets ranged up to USD 1 mil in budget, and durations ranged between 5 months and a year, not including preparation phases (such as a sales process). All projects involved project teams from multiple geographic locations, from 3-5 countries and 2-3 time zones, including external contractors.

Due to the small sample size, only limited statistical analysis is applicable. If the averages and the range are examined, it is noteworthy that the projects differ in their VUCA-lity, indicating that the VUCA meter statements do capture the risk factors that could be embedded in the risk control mechanism of the organization. The numerical results of the research are presented in Table 2 and in Table 3 the scores and accuracy estimation of the five project managers are shown. 


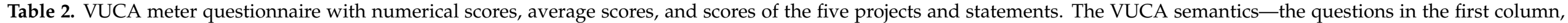
reflecting the four dimensions of the VUCA framework—are based on Bennett and Lemoine [32,40].

\begin{tabular}{|c|c|c|c|c|c|c|c|}
\hline \multirow{2}{*}{$\begin{array}{c}\text { Criteria } \\
\text { Volatility }\end{array}$} & \multicolumn{5}{|c|}{ Compliance Weights } & \multirow[t]{2}{*}{ Average Score } & \multirow[t]{2}{*}{ Statement Score Rang } \\
\hline & 1 & 2 & 3 & 4 & 5 & & \\
\hline Simple in planning (straightforward/sequential execution) & 5 & 5 & 5 & 4 & 5 & 4.8 & 1 \\
\hline Resource needs are known and accessible & 2 & 4 & 4 & 4 & 2 & 3.2 & 2 \\
\hline Adequate timeframe with good slack in schedule & 3 & 4 & 4 & 2 & 4 & 3.4 & 2 \\
\hline Solid contracts throughout project duration & 2 & 2 & 5 & 2 & 5 & 3.2 & 3 \\
\hline Known, well defined objectives & 2 & 1 & 4 & 2 & 2 & 2.2 & 3 \\
\hline Average score: & 2.8 & 3.2 & 4.4 & 2.8 & 3.6 & & \\
\hline Project score range: & 3 & 4 & 1 & 2 & 3 & & \\
\hline Uncertainty & 1 & 2 & 3 & 4 & 5 & & \\
\hline Uses few and proven technology components & 5 & 4 & 5 & 4 & 2 & 4 & 3 \\
\hline Stakeholders are few, with few time zones/cultural differences & 5 & 5 & 5 & 4 & 5 & 4.8 & 1 \\
\hline Information is easy to obtain & 3 & 4 & 4 & 4 & 5 & 4 & 2 \\
\hline Scope is well defined and approved & 2 & 1 & 2 & 2 & 4 & 2.2 & 3 \\
\hline Average score: & 3.8 & 3.2 & 4 & 3.4 & 4 & & \\
\hline Project score range: & 3 & 4 & 3 & 2 & 3 & & \\
\hline Complexity & 1 & 2 & 3 & 4 & 5 & & \\
\hline Few and simple regulatory or political environments & 5 & 5 & 2 & 2 & 4 & 3.6 & 3 \\
\hline Few subcontractors, organizational departments, and cultural differences & 5 & 5 & 2 & 2 & 5 & 3.8 & 3 \\
\hline Few interfaces with other technologies, projects or operations & 5 & 5 & 5 & 2 & 4 & 4.2 & 3 \\
\hline Has been done many times before & 4 & 3 & 2 & 4 & 4 & 3.4 & 2 \\
\hline Clear governance, straightforward decision-making & 3 & 1 & 4 & 2 & 4 & 2.8 & 3 \\
\hline
\end{tabular}


Table 2. Cont.

\begin{tabular}{|c|c|c|c|c|c|c|c|}
\hline Criteria & \multicolumn{5}{|c|}{ Compliance Weights } & Average Score & Statement Score Range \\
\hline Average score: & 4.4 & 3.8 & 3 & 2.4 & 4.2 & & \\
\hline Project score range: & 2 & 4 & 3 & 2 & 1 & & \\
\hline Deliverables are well defined, no "unkowns unkowns" & 5 & 2 & 4 & 3 & 5 & 3.8 & 3 \\
\hline Connections between tasks are clear & 2 & 4 & 3 & 2 & 2 & 2.6 & 2 \\
\hline Risk factors are well known and documented & 4 & 2 & 4 & 4 & 5 & 3.8 & 3 \\
\hline No "hidden agenda" & 2 & 3 & 4 & 2 & 5 & 3.2 & 3 \\
\hline All stakeholders and their relationships are recognized & 2 & 2 & 3 & 2 & 3 & 2.4 & 1 \\
\hline Average score: & 3 & 2.6 & 3.6 & 2.6 & 4 & & \\
\hline Project score range: & 3 & 2 & 1 & 2 & 3 & & \\
\hline
\end{tabular}


Table 3. The scores and accuracy estimation of the five project managers.

\begin{tabular}{ccccccccc}
\hline Projects & \multicolumn{2}{c}{ Volatility } & \multicolumn{2}{c}{ Uncertainty } & \multicolumn{2}{c}{ Complexity } & \multicolumn{2}{c}{ Ambiguity } \\
\hline Project \# & Score & Accuracy & Score & Accuracy & Score & Accuracy & Score & Accuracy \\
\hline 1 & 2.8 & High & 3.8 & High & 4.4 & High & 3.0 & High \\
\hline 2 & 3.2 & High & 3.2 & High & 3.8 & High & 2.6 & High \\
\hline 3 & 4.4 & High & 4.0 & High & 4.0 & High & 3.6 & High \\
\hline 4 & 2.8 & High & 3.4 & High & 2.4 & High & 2.6 & High \\
\hline 5 & 3.6 & High & 4.0 & High & 4.2 & High & 4.0 & High \\
\hline
\end{tabular}

Volatility: Two project managers (no. 1 and 2) indicated that the volatility was accurate, but in reviewing the results, they might be slightly lower. However, both also stated that it could be lower due to the experience and culture that facilitate resource slack (mitigating approach), not because the measurement of complexity was inaccurate. Statement phrasing might be re-evaluated based on this, so that indications of existing practices to mitigate the risk are reflected in the rating.

Uncertainty: In interviews, two project managers (no. 3 and 4) emphasized the impact of uncertainty on the other risk factors in the project. The impact of uncertainty on volatility was discussed, as a lack of reliable information in the projects had a direct impact on resource needs, which in turn magnifies the impact of volatility in resources.

Complexity: One project manager (no. 3) stated that the score for complexity may have needed to be higher, although its relative value compared to other categories was accurate. In discussing the complexity and scores, the complexity factor of organizational departments could be better phrased to indicate the organizational complexity of globally operating companies. This was a site of some complexity, though the VUCA impact was most felt in the uncertainty dimension, as the complexity led to unreliable information assumptions. In addition, phrasing could be adjusted to also represent projects involving multiple companies where one organization is leading the project management.

Ambiguity: Three project managers (no. 1,2, and 4) indicated that the ambiguity score, while lower than might have been expected given the nature of the projects, gave an accurate depiction of the ambiguity reflected by project actuals (time, cost, progress). The subjects stated that strong application and experience of project management methodologies and the clear structure of the projects were the reasons for this.

The average VUCA risk assessment score in the project as calculated was as follows in Table 4:

Table 4. The average VUCAlity of the five projects.

\begin{tabular}{cc}
\hline Project \# & VUCA Score \\
\hline 1 & 3.50 \\
\hline 2 & 3.20 \\
\hline 3 & 3.75 \\
\hline 4 & 2.80 \\
\hline 5 & 3.95 \\
\hline
\end{tabular}

The project managers did not see much value in a single numerical score but stated that graphical charts showing the relative severity of dimensions within the projects were useful. They found the graphics to give a very accurate picture of the project challenges and a good indication of where to take a deeper look at the risks at hand. Figures 1 and 2 show two types of graphical illustrations for projects 1-5. 


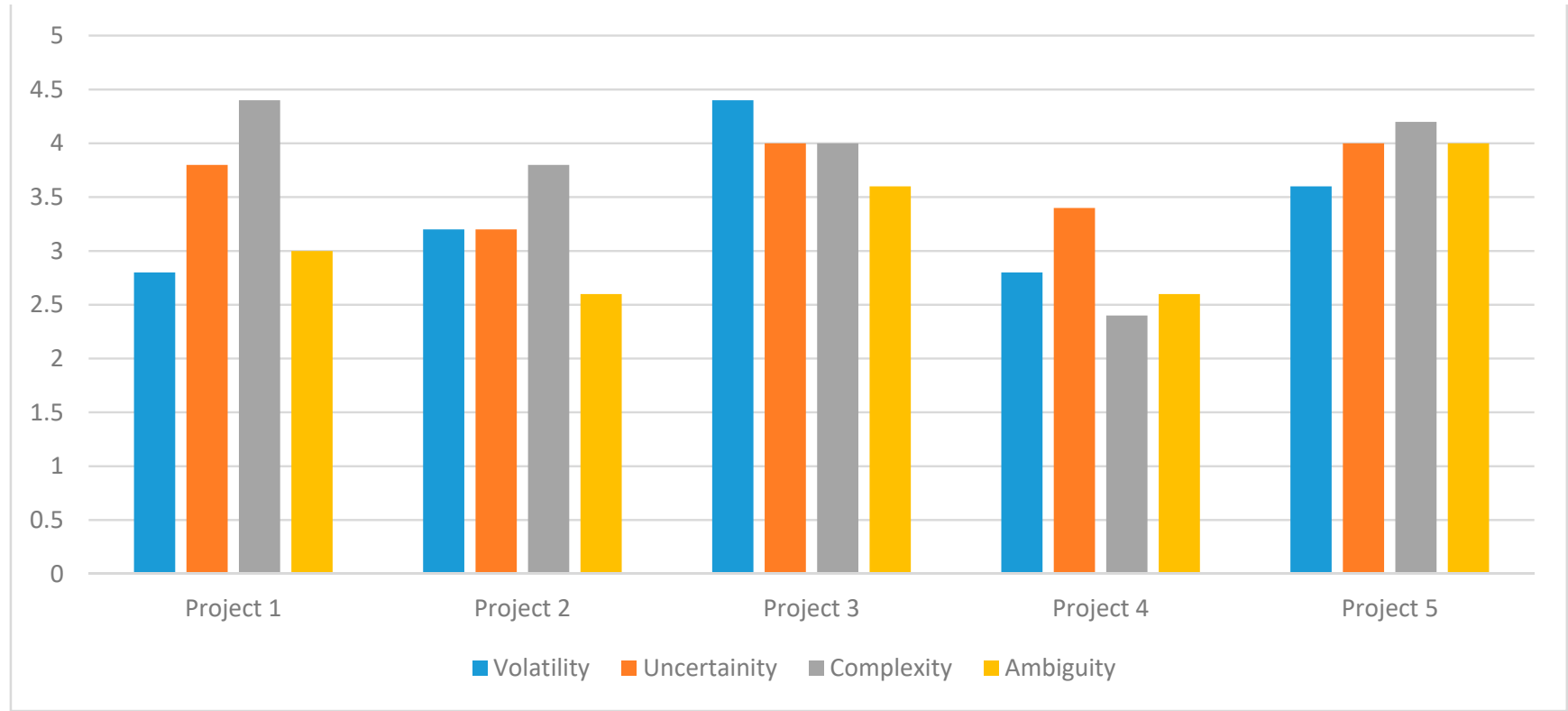

Figure 1. Graphical illustration of VUCA score for projects 1-5 in bar charts.

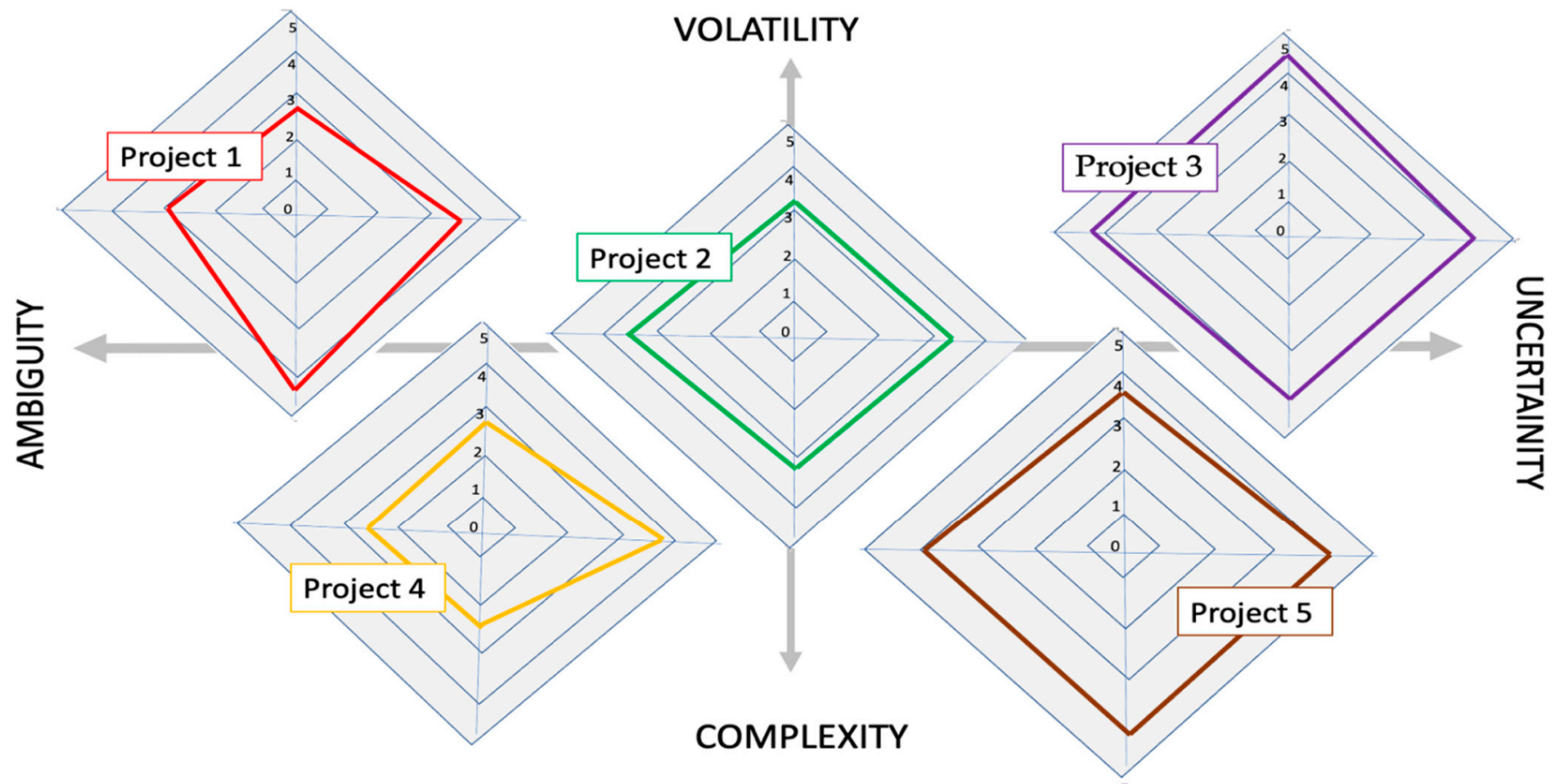

Figure 2. Graphical illustration of VUCA score for projects 1-5 in radar charts.

Three statements have very low range of scoring across all projects: The statements involve sequential planning, distributed stakeholders, and recognition of stakeholder relationships. Uniformity in scores on stakeholders across cultures and time zones may be explained by the fact that the organization in question is globally operating and few complex projects within the organization involve only one location. Sequential planning scores may similarly be explained with the nature of the projects under investigation. The final statement in the questionnaire has no strong answer scores and could be refined to further draw out the potential complexity of the ambiguity dimension. Further testing should be conducted to examine if the range remains uniform in other organizations that deal with complex projects. 


\section{Discussion and Conclusions}

Interviews with all the participants who took part in the survey indicated a strong confidence in which each aspect of the projects under investigation could be situated in the VUCA risk assessment matrix. The suggested graphical representations of the severity score for each of the VUCA dimensions was, by participants, described as the most useful result of applying the VUCA method. Through such a picture, the comparative severity of each dimension became clear, and the illustration was, by all participants, rated as highly accurate. The overall trends in weights indicated high internal consistency of statement scores and the comparison of scores across projects indicated that the subjective evaluation influences the numerical score. Numerical scores without context, however, were described as less helpful. While the intervals between ratings were accurate, the tool was deemed as limited by the fact that evaluation was somewhat subjective, and the strength of numerical values is influenced by the experience of each participant. For example, a participant might be prone to avoid extremes when answering questions on the scale, and so the subjective nature of evaluation can lead to higher/lower numerical scores for all answers. However, as all the scores are given by the same person, the relationship between the severity of dimensions could be deemed as accurate. The individual numerical scores are therefore less useful, and the value was seen in the relative difference between VUCA dimensions. The total average score is therefore also not of value for the measurement.

The overall results of the study are that the VUCA paradigm is useful for evaluating risk, gathering information to define the project scope, and communicating project challenges to stakeholders. The study also indicates that the VUCA meter can be a valuable preface or addition to more traditional risk assessment methods, adding constructive information regarding the risk events and their impact on the equation. Our findings indicate that the VUCA meter can "open up" the somewhat traditional line of thinking in project management risk assessment and help future project managers to better assess the dynamic project environment and allow for better predictions and more realistic impact assessments of the impact of the VUCA environment. Moreover, the study paves the way for further research on how to improve the meaning of VUCA for project and program management by, for instance, clearly differentiating between the different categories of the VUCA measurement, in order to compare projects assessed solely with traditional risk identification with projects assessed with VUCA. The VUCA approach could still further, if used appropriately for improvement, help with the much-needed risk identification and control that are needed as a quality assurance on the critical path the project management profession should follow towards a more sustainable world.

Author Contributions: Conceptualization, T.V.F. and B.H.K.; methodology, H.I.J.; validation, H.T.I., H.I.J. and T.V.F.; formal analysis, B.H.K.; investigation, B.H.K.; writing-original draft preparation, B.H.K.; writing-review and editing, H.I.J.; visualization, H.I.J.; supervision, T.V.F.; project administration, H.T.I. All authors have read and agreed to the published version of the manuscript.

Funding: This research did not receive any external funding. It is however linked to the DecisionShip Ahoy project that is co-funded by the Erasmus+ program of the European Union [40].

Institutional Review Board Statement: The study was conducted according to the guidelines of the Declaration of Helsinki and approved in accordance with the requirements of the Institutional Review Department of Reykjavik University (RU-MPM-Review-Board-May 2020, 1 May 2019).

Informed Consent Statement: Informed consent was obtained from all subjects.

Data Availability Statement: The data supporting reported results can be obtained from the corresponding author.

Acknowledgments: The authors would like to acknowledge their colleagues from the DecisionShip Ahoy project, co-funded by the Erasmus+ program of the European Union [40]. The European Commission support to produce this publication does not constitute an endorsement of the contents which reflect the authors' views only, and the Commission cannot be held responsible for any use which may be made of the information contained therein. 
Conflicts of Interest: We declare that we ensured the objectivity and transparency in our research and that accepted principles of ethical and professional conduct have been followed. Prior informed consent was obtained from individual participants included in the study before the research. No sensitive personal data were accessed. Anonymity of individual participant data is maintained.

\section{Appendix A}

Table A1. VUCA concepts and definitions.

\begin{tabular}{|c|c|c|c|}
\hline Categories & What It Is & An Example & Recommended Response \\
\hline Volatility & $\begin{array}{l}\text { Relatively unstable changes, } \\
\text { information is available, and the } \\
\text { situation is understandable, but } \\
\text { change is frequent and sometimes } \\
\text { unpredictable. }\end{array}$ & $\begin{array}{l}\text { Commodity pricing is often quite } \\
\text { volatile; jet fuel costs, for instance, } \\
\text { have been quite volatile in the } 21 \text { st } \\
\text { century. }\end{array}$ & $\begin{array}{l}\text { Agility is key to coping with volatility. } \\
\text { Resources should be aggressively } \\
\text { directed toward building slack and } \\
\text { creating the potential for future } \\
\text { flexibility. }\end{array}$ \\
\hline Uncertainty & $\begin{array}{l}\text { A lack of knowledge as to whether } \\
\text { an event will have meaningful } \\
\text { ramifications; cause and effect are } \\
\text { understood, but it is unknown if an } \\
\text { event will create significant change. }\end{array}$ & $\begin{array}{l}\text { Anti-terrorism initiatives are } \\
\text { generally plagued with uncertainty; } \\
\text { we understand many causes of } \\
\text { terrorism but not exactly when and } \\
\text { how they could spur attacks. }\end{array}$ & $\begin{array}{l}\text { Information is critical to reducing } \\
\text { uncertainty. Firms should move } \\
\text { beyond existing information sources } \\
\text { to both gather new data and consider } \\
\text { them from new perspectives. }\end{array}$ \\
\hline Complexity & $\begin{array}{l}\text { Many interconnected parts, forming } \\
\text { elaborate networks of information } \\
\text { and procedures; often multiform } \\
\text { and convoluted but not necessarily } \\
\text { involving change. }\end{array}$ & $\begin{array}{l}\text { Moving into foreign markets is } \\
\text { frequently complex; doing business } \\
\text { in new countries often involves } \\
\text { navigating a complex web of tariffs, } \\
\text { laws, regulations, and logistics } \\
\text { issues. }\end{array}$ & $\begin{array}{l}\text { Restructuring internal company } \\
\text { operations to match external } \\
\text { complexity is an effective and } \\
\text { efficient way to address. Firms } \\
\text { should attempt to "match" their own } \\
\text { operations and processes to mirror } \\
\text { environmental complexities. }\end{array}$ \\
\hline Ambiguity & $\begin{array}{l}\text { Lack of knowledge as to the "basic } \\
\text { rules of the game"; cause and effect } \\
\text { are not understood and there is no } \\
\text { precedent for making predictions as } \\
\text { to what to expect. }\end{array}$ & $\begin{array}{l}\text { Transition from print to digital } \\
\text { media has been very ambiguous; } \\
\text { companies are still learning how } \\
\text { customers will access and } \\
\text { experience data and entertainment } \\
\text { given new technologies. }\end{array}$ & $\begin{array}{l}\text { Experimentation is necessary for } \\
\text { reducing ambiguity. Only through } \\
\text { intelligent experimentation can firm } \\
\text { leaders determine what strategies are } \\
\text { and are not beneficial in situations } \\
\text { where former rules of business no } \\
\text { longer apply. }\end{array}$ \\
\hline
\end{tabular}

Definitions laid out by the authors based on Bennett and Lemoine (2014) [39].

\section{References}

1. Midler, C. Projectification of the firm: The Renault case. SJM 1995, 11, 363-375. [CrossRef]

2. Wald, A.; Schneider, C.; Spanuth, T.; Schoper, Y. Towards a Measurement of "Projectification": A Study on the Share of ProjectWork in the German Economy. In Advanced Project Management: Flexibility and Innovative Capacity; Wald, A., Wagner, R., Schneider, C., Gschwendtner, M., Eds.; GPM: Nürnberg, Germany, 2015; Volume 4, pp. 18-36.

3. Schoper, Y.G.; Wald, A.; Ingason, H.T.; Fridgeirsson, T.V. Projectification in Western economies: A comparative study of Germany, Norway and Iceland. Int. J. Proj. Manag. 2018, 36, 71-82. [CrossRef]

4. Morris, P.W.G.; Pinto, J.; Söderlund, J. (Eds.) Towards the Third Wave of Project Management. In Oxford Handbook of Project Management; Oxford University Press: Oxford, UK, 2012; pp. 1-11.

5. ISO-International Organization for Standardization (2020). Iso Standards Are Internationally Agreed By Experts. 2020. Available online: https: / / www.iso.org/standards.html (accessed on 1 February 2021).

6. Flyvbjerg, B. From Nobel Prize to Project Management: Getting Risks Right. Proj. Manag. J. 2006, 37, 5-15. [CrossRef]

7. Flyvbjerg, B. Over budget, over time, over and over again. In The Oxford Handbook of Project Management; Morris, P.W., Pinto, J.K., Söderlund, J., Eds.; Oxford University Press: Oxford, UK, 2011; pp. 321-344.

8. PMI. Project Management Institute: Foundational Standards; PMI: Newtown Square, PA, USA, 2017. Available online: https: //www.pmi.org/pmbok-guide-standards/foundational (accessed on 1 February 2021).

9. PMI. Project Management Institute, The Standard for Risk Management in Portfolios, Programs, and Projects; PMI: Newtown Square, PA, USA, 2020. Available online: https:/ / www.pmi.org/pmbok-guide-standards/foundational/risk-management (accessed on 1 February 2021).

10. APM. APM Body of Knowledge, 7th ed.; 2018. Available online: https://www.apm.org.uk/media/24069/bok7-whats-changedakt11950-with-links.pdf (accessed on 1 February 2021). 
11. Ackerman, F.; Eden, C.; Williams, T.; Howick, S. Systematic Risk Assessment: A Case Study. J. Oper. Res. Soc. $2007,58,39-51$. [CrossRef]

12. Cirillo, P.; Taleb, N. Tail risk of contagious diseases. Nat. Phys. 2020, 16, 606-613. [CrossRef]

13. Cooke-Davies, T.; Cicmil, S.; Crawford, L.; Richardson, K. We're not in Kansas anymore, Toto: Mapping the strange landscape of complexity theory, and its relationship to project management. Proj. Manag. J. 2007, 38, 50-61. [CrossRef]

14. Williams, T.M. The need for new paradigms for complex projects. Int. J. Proj. Manag. 1999, 17, 269-273. [CrossRef]

15. Brady, T.; Davies, A. Managing structural and dynamic complexity: A tale of two projects. Proj. Manag. J. 2014, 45, 21-38. [CrossRef]

16. Tatikonda, M.V.; Rosenthal, S.R. Technology novelty, project complexity, and product development project execution success: A deeper look at task uncertainty in product innovation. IEEE Trans. Eng. Manag. 2000, 47, 74-87. [CrossRef]

17. Turner, J.R.; Cochrane, R.A. Goals and methods matrix: Coping with projects with ill-defined goals and/or methods of achieving them. Int. J. Proj. Manag. 1993, 11, 93-102. [CrossRef]

18. Remington, K.; Zolin, R.; Turner, R. A model of project complexity: Distinguishing dimensions of complexity from severity. In Proceedings of the International Research Network of Project Management Conference, Berlin, Germany, 11-13 October 2009.

19. Baccarini, D. The concept of project complexity-A review. Int. J. Proj. Manag. 1996, 14, 201-204. [CrossRef]

20. Shtub, A.; Bard, J.F.; Globerson, S. Project Management: Engineering, Technology, and Implementation; Prentice Hall: Englewood Cliffs, NJ, USA, 1994.

21. Geraldi, J. Patterns of complexity: The thermometer of complexity. Proj. Perspect. 2008, 24, 4-9.

22. Geraldi, J.G.; Adlbrecht, G. On faith, fact, and interaction in projects. Proj. Manag. J. 2007, 38, 32-43. [CrossRef]

23. Morris, P.W.G.; Geraldi, J.G. Managing the institutional context for projects. Proj. Manag. J. 2011, 42, 20-32. [CrossRef]

24. Fitsilili, P. Measuring the complexity of software projects. In Proceedings of the WRI World Congress on Computer Science and Information Engineering, Computer Science and Information Engineering, Los Angeles, CA, USA, 31 March-2 April 2009; Volume 7, pp. 644-648.

25. Pollak, J. The changing paradigms of project management. Int. J. Proj. Manag. 2007, 25, 266-274. [CrossRef]

26. Jonasson, H.I.; Ingason, H.T. Project Ethics; Routledge/Taylor and Francis: Abingdon, UK, 2013.

27. Bosch-Rekveldt, M.J. Grasping project complexity in large engineering projects: The TOE (Technical, Organizational and Environmental) framework. Int. J. Proj. Manag. 2011, 29, 728-739. [CrossRef]

28. Bosch-Rekveldt, M.; Bakker, H.; Hertogh, M. Comparing Project Complexity Across Different Industry Sectors. Complexity 2018, 2018, 3246508. [CrossRef]

29. Bosch-Rekveldt, M.; Mooi, H.G.; Verbraeck, A.; Sjoer, E.; Wolsing, B.; Gulden, C. Mapping project manager's competences to project complexity. In Proceedings of the IPMA 23rd World Congress Proceedings, Research Track Human Side of Projects in Modern Business, Helsinki, Finland, 15-17 June 2009; Kakonen, K., Ed.; Project Management Association Finland (PMAF) and VTT Technical Research Centre of Finland: Helsinki, Finland, 2009.

30. Bennis, W.; Nanus, B. Leaders: Strategies for Taking Charge; HarperCollins: New York, NY, USA, 1985.

31. U.S. Army Heritage and Education Center: USAHEC Ask Us a Question. Available online: http://usawc.libanswers.com/faq/84 869 (accessed on 1 February 2021).

32. Bennett, N.; Lemoine, G.J. What VUCA Really Means for You. Harv. Bus. Rev. 2014, 92.

33. Forbes. What Does VUCA Really Mean? Available online: https://www.forbes.com/sites/jeroenkraaijenbrink/2018/12/19 / what-does-vuca-really-mean/?sh=7fbd6f2c17d6 (accessed on 1 February 2021).

34. Szpitter, A.; Sadkowska, J. Using VUCA matrix for the assessment of project environment risk. Zarzadzanie Finanse 2013, 14, 401-413.

35. Mikkelsen, M.F.; Marnewick, C.; Klein, K. On Stupidity in Project Management-A critical reflection of PM in a VUCA world. J. Mod. Proj. Manag. 2020, 8, 2.

36. Mack, O.; Jungen, M. Program management in VUCA environments: Theoretical and pragmatical thoughts on a systemic management of projects and programs. In Managing in a VUCA World; Mack, O., Khare, A., Krämer, A., Burgartz, T., Eds.; Springer: Cham, Switzerland, 2016; pp. 41-57.

37. Bierwolf, R.; Romero, D.; Pelk, H.; Stettina, C.J. On the future of project management innovation: A call for discussion towards project management 2030. In Proceedings of the International Conference on Engineering, Technology and Innovation (ICE/ITMC), Madeira, Portugal, 27-29 June 2017; pp. 689-698.

38. Bennett, N.; Lemoine, G.J. What a Difference a Word Makes: Understanding Threats to Performance in a VUCA World. Bus. Horizons 2014, 57, 311-317. [CrossRef]

39. Allen, E.; Seaman, C. Likert Scales and Data Analyses. Qual. Prog. 2007, 40, 64-65.

40. An Elite Technological University. European Project: DecisionShip Ahoy! 2017-2020. Available online: www.dahoyproject.eu (accessed on 1 February 2020). 